\title{
¿SIGUIÓ EL CÓDIGO CIVIL FRANCÉS EL PENSAMIENTO DE DOMAT EN MATERIA DE CULPA (FAUTE) EXTRACONTRACTUAL?
}

\author{
DID THE CIVIL FRENCH CODE FOLLOW, DOMAT'S THOUGHT ON \\ NEGLIGENCE (FAUTE)?
}

\section{Cristián Aedo Barrena*}

\begin{abstract}
RESUMEN: El presente trabajo plantea una revisión a la tesis tradicional, que afirma que las reglas de responsabilidad del Code y, en particular, el contenido de la faute, fue tomado de Domat. El artículo hace una breve revisión de la historia de la codificación francesa y la consagración de la faute en su articulado, las posiciones doctrinarias en relación con el fundamento filosófico que mueve sus normas y cómo estas posiciones impactan en las reglas de responsabilidad. Finalmente, la tercera parte está dedicada a argumentar, desde la perspectiva metodológica, antropológica y filosófica la idea de que el Code, aun cuando sigue el trabajo de sistematización de Domat, no incorporó sus ideas y visión filosófica y moral, lo que en definitiva se ha traducido en una lectura errónea de la culpa.
\end{abstract}

Palabras clave: Code, responsabilidad, faute, culpa

\begin{abstract}
This paper proposes a revision to the traditional view, which states that the liability rules of the Code and in particular, the content of faute, was taken from Domat. The article makes a brief review of the history of the French codification and the consecration of the faute in its provisions, the doctrinal positions regarding the philosophical foundation that moves its rules and how they impact positions on the liability rules. Finally, the third part is dedicated to argue, from the methodological, anthropological and philosophical perspective the idea that the Code, even when you follow the work of systematization of Domat, did not incorporate their ideas and philosophical and moral vision, which ultimately is It has resulted in an erroneous reading of the fault.
\end{abstract}

Key words: Code, responsibility, faute, negligence

\section{INTRODUCCIÓN}

Tradicionalmente se ha aseverado que, en materia de responsabilidad civil y, particularmente, en el ámbito de la culpa (faute), el Código Napoleón siguió, como en otras materias, las ideas jurídicas de Domat y, todavía más, la perspectiva ética del jurista francés ${ }^{1}$. Al ser uno de los grandes modelos codificados del Derecho continental, esta visión de la culpa se habría traspasado a sus homólogos, lo que le valdría las críticas posteriores de la tradi-

\footnotetext{
* Doctor en Derecho por la Universidad de Deusto. Profesor de Derecho romano y Derecho civil de la Facultad de Ciencias Jurídicas, Escuela de Derecho Antofagasta, de la Universidad Católica del Norte. Dirección postal: Avenida Angamos 0610, Antofagasta. Correo electrónico: caedo@ucn.cl.

1 Por todos, Mazeaud y Tunc (1977) Tomo I, vol. 1, pp. 59 y ss.
} 
ción civilista ${ }^{2}$. Se argumenta, además, que la regla general de responsabilidad civil, fundada en la culpa, se funda en la tradición jurídica domatiana ${ }^{3}$, lo que equivale a identificar al autor, con la corriente del Derecho natural racionalista ${ }^{4}$.

El propósito de este trabajo es poner en cuestión la tesis tradicional. En materia de responsabilidad civil, el Code emplea la expresión faute y en ello coincide naturalmente con Domat: dada su filiación a la gramática de Port Royal, Domat escribió en francés, lengua que no incorporó el sustantivo latino culpa, como harían las restantes lenguas romances 5 . No obstante, como se argumentará en este trabajo, no puede asumirse que el Code acogiera la perspectiva metodológica, la visión ética y la antropología de Domat, autor complejo que a su vez recoge sus ideas del racionalismo naturalista, del pesimismo jansenista de Pascal y del empirismo, sin seguir exclusivamente ninguno de estos referentes. Ni el repudio de la racionalidad de Pascal, ni un exclusivo empirismo mecanicista, ni la secularidad propia del iusnaturalismo racionalista encuentran en Domat acogida completa, como analizaremos detalladamente.

Para ocuparnos de este problema, examinaremos brevemente la génesis (en los distintos proyectos del Code) de las reglas de responsabilidad civil que se consagraron en definitiva en el Code y el lugar que la faute (culpa) ocupó entre las reglas de imputación de daños. Este breve contexto permitirá examinar las lecturas que, con posterioridad a la vigencia del Código civil francés surgieron en relación con la responsabilidad civil aquiliana y el rol que le cupo en ella a la culpa. La tesis tradicional, como se ha sostenido, elabora como paradigma la idea de la culpa como criterio subjetivo de reproche moral para el autor, lo que respondería a una sociedad individualista y preindustrial. En la última parte del trabajo, argumentaremos contra esta tradicional posición, especialmente contra la idea de que la culpa (faute) se funda en el pensamiento ético, filosófico y jurídico de Domat.

\footnotetext{
2 Para esta cuestión, remitimos a nuestro trabajo Aedo (2014) pp. 21-22, especialmente nota 2.

3 Por todos, Viney (1998) p. 11. Para la obra de Domat como modelo del Code, véase Cousin (1845) p. 57. Ciertamente, la elaboración de una cláusula general de responsabilidad, de acuerdo con la cual todo daño debía ser indemnizado si era causado con culpa, se debe a la Escuela del Derecho natural racionalista, comenzando por Grocio (por todos, Halpérin (1992) pp. 57-58). Con todo, la formulación de dicho principio no surge espontáneamente con esta escuela, sino que se debe a un trabajo progresivo de los comentadores. Como explica HespHANA (2002) pp. 131-132, mediante la dialéctica, los comentaristas harán un trabajo de sistematización e inducción de las definiciones y principios, quedando allanado el camino a los humanistas para la deducción de principios generales, lo que explicaría, consideramos, el porqué los códigos de los ochocientos, aunque inspirados en el iusnaturalismo racionalista, contienen categorías claramente aristotélicas. Para las fuentes romanas y su pervivencia, remitimos a nuestro trabajo Aedo (2009) pp. 311 y ss.; Aedo (2012) pp. 777 y ss.; y, Aedo (2014) pp. 27 y ss.

4 Véase, por todos, Rogel (2010) pp. 186 y ss.

5 Siguiendo a Tarello (1976) p. 174, en la metodología de Domat el Derecho romano debía ser reducido a principios racionales ligados a un sistema unido por el espíritu, con la idea que para hacer esto, debía concurrir una lengua capaz de expresar y reproducir con claridad la realidad. Esa lengua era el francés. Como indica el Tarello, Domat recoge este pensamiento de la lingüística jansenista de Port Royal. Como señala Renoux-Zagamé (1993) p. 57, para edificar su obra, Domat va a utilizar el Derecho romano común, que constituirá, por consiguiente, la base de la codificación europea.
} 


\section{EL CONTEXTO HISTÓRICO: DESDE LOS PROYECTOS DE CÓDIGO CIVIL HASTA LA CONSAGRACIÓN DE LAS REGLAS DE CULPA}

\section{A. Breve referencia a la historia y estructura del Code}

Los afanes codificadores en Francia surgen muy temprano. En efecto, siguiendo a Fenet, el 24 de junio de 1793, la Convención introduce un artículo a la Constitución por el que se ordenaba la redacción de un Código para toda la República. Se nombra una Comisión Legislativa, compuesta por 48 miembros y presidida por Cambacérès, que presenta un proyecto el 9 de agosto de 1793. El 3 de noviembre se designa una comisión de 6 miembros que revisa el trabajo del Comité de Legislación ${ }^{6}$. Este motivo conduce a que se nombre una nueva Comisión, de 7 miembros, el 9 de fructidor. Cambacérès presenta un nuevo proyecto, el 23 de fructidor del año II (9 de septiembre de 1794) cuyo objeto era la reducción de las reglas hasta los principios que uno pudiese esperar en la vida diaria. Mientras al primer proyecto se le reprochó su carácter complejo, su estilo filosófico, al segundo, por el contrario, su carácter simple y estilo lapidario. El objeto fundamental de este segundo proyecto, como reza en el mensaje dirigido por Cambacérès, era: "Regler las rélations des citoyens avec la société, c'est établir l'ordre politique. Régler las rapports des citoyens entre eux, c'est établir l'ordre civil et fonder l'odre moral".

Los ejes sobre los cuales giró dicho proyecto, de acuerdo con el mensaje, fueron las materias relativas a las personas, la propiedad y la convención, considerados como los objetos de regulación de la legislación civil. Nuevamente, las cuestiones relativas a la responsabilidad -especialmente la culpa-, recibieron un tratamiento completamente tangencial e incluso esta última ni siquiera era mencionada, pues el fundamental principio inspirador de dicha codificación fue la libertad de las partes y el deber de respetar los pactos ${ }^{7}$.

Avanzados los trabajos del Comité de Legislación hasta este punto, asume el Directorio. En el seno del Consejo de los Quinientos, se nombra una nueva comisión, cuyo objeto era clasificar y simplificar las leyes civiles, el 24 de Prainal del año IV. Así, en el seno de la Comisión de clasificación de las leyes nace un nuevo proyecto, que sirve de base fundamental al proyecto definitivo y el que contaba, esta vez, con 1104 artículos ${ }^{8}$.

La discusión del nuevo proyecto, también de Cambacérès, comienza finalmente el 10 de vendimario del año $\mathrm{V}$ y se produce entre el 9 pluvioso y el 8 de ventoso, aunque tampoco tuvo suerte, pues solo dos de sus artículos fueron decretados, el 18 y 19 de brumario (9 y 10 de noviembre de 1799). La Constitución de 22 de frimario organiza, de manera definitiva, el sistema de gobierno. La Constitución entró en vigor el 4 de nivoso

\footnotetext{
6 Fenet (1856) Tomo I, pp. xxxv-xlvi; 1-12; 64-65. El artículo 3 del proyecto agregaba que: "Il y a des faits qui obligent sans convention, et par la seule équité; ainsi l'absent, dont un tiers a géré utilement les affaires sans mandat, est obbligé à l'indemniser de ses dépenses. Ainsi, tout homme qui a causé du dommage à un autre, dans sa personne ou dans ses biens, est obligé à le réparer". El proyecto fue finalmente rechazado.

7 Véase Fenet (1856) Tomo I, pp. 99-100; 124.

8 En relación con la materia que analizamos, los ejes sobre los cuales giraba el proyecto eran muy similares, por cuanto, el artículo 758 prescribía que había obligaciones que nacían sin convención, en virtud de la ley o la sola equidad. Junto con el tratamiento de los denominados cuasicontratos, el artículo 745 consagraba la obligación de indemnizar en los siguientes lacónicos términos: "Celui qui cause un dommage est tenuà la réparer, quel que soit le fait qui y donne lieu”. Véase FEnET (1856) Tomo I, pp. 124 y ss.
} 
del año VIII, cesando su existencia la Comisión Legislativa. Bonaparte, que había tomado el lugar del Primer Cónsul, reemprende el trabajo de la codificación civil. El 24 de termidor (12 de agosto de 1800) se nombra la Comisión encargada de la preparación del Code: "Art. 1. Le ministre de la justice réunira dans la maison du ministère, MM. Tronchet, président du Tribunal de cassation; Bigot-Préamenau, commisaire du gouvernement près ce Tribunal; et Portalis, commissaire au Conseil des prises, pour y tenir des conférences sur la rédaction du Code Civil. Art. 2, il appellera à ces conferences M. Malleville, membre du Tribunal de cassation, lequel remplira les functions secrétaire rédacteur". Una vez hecha la redacción por la Comisión designada, el trabajo fue revisado tanto por el Consejo de Estado, como por el Tribunal de Casación y los Tribunales de Apelación. La materia objeto de nuestro estudio quedó establecida en la sección segunda, Des Délits et des Quasi-délits, artículos 15-20. El referido proyecto fue sometido a la revisión y comentarios de los distintos tribunales de apelación, así como al Consejo de Estado. En relación con los tribunales de apelación, sus opiniones contribuyeron a la descartar del texto definitivo figuras correspondientes a los cuasidelitos romanos, como ocurría con los artículos 16 y 17 del proyecto9. Por ejemplo, el Tribunal de Apelación de Agen, en relación con los artículos 17, 18 y 19, estimó: "Les faits énoncés dans ces articles son des délits de pólice qui donnent essentiellement licu à une action publique; ainsi ils ne peuvent être rapportés parmi les quasidélits".

Lo cierto es que, en la discusión del articulado, ante el Consejo de Estado, los artículos 17 y 18 del proyecto fueron abandonados, a instancias de M. Mior: "M. Mior dit que l'énonciation du principle suffit; que les exemples doivent être retranchés". Se consideró, de este modo, que la enumeración casuística de los supuestos debía ser eliminada, al quedar subsumida en las hipótesis generales. Los restantes artículos, con algunas variaciones menores, son aprobados.

Una vez que este acabó dicha revisión, en la materia objeto de nuestro análisis, Brigot de Préameneu presenta el Título IV del Libro III, sección segunda, "Des Délits et des Quasi-délits", artículos 15 a 18. El artículo 15, enumerado finalmente como 1382, conservó su redacción original. En cuanto al artículo 16, adoptado del artículo 18 del proyecto original, fue modificado en el encabezado. El artículo 17, con algunas variaciones menores, fue adoptado del artículo 19 de la relación verbal, mientras que el artículo 18 adoptó idéntica redacción del artículo 20 del proyecto antes descrito. Finalmente, en la redacción definitiva del Consejo de Estado y debido a la supresión de otras normas del título respectivo, los artículos en cuestión fueron presentados con los números 13 (1382), 14 (1383), 15 (anteriormente, artículo 17, correspondiente al artículo 1384), 16 (fue separado el inciso final del artículo 15, relativo a la responsabilidad por el hecho de los animales, pasando a ser el artículo 1385); y, 17 (artículo 1386, adoptado del artículo 18) ${ }^{10}$.

\footnotetext{
9 Puede afirmase, con mediana seguridad que las aportaciones en la materia objeto de nuestro estudio, no fueron sustantivas. Así se deduce, por ejemplo, del estudio que efectúa sobre el punto, Halpérin (1996) pp. 20-23. Ello resulta también del examen de Fenet (1856) Tomo III, pp. 1 y ss., en el que se incluyen las observaciones de los distintos tribunales.

10 Véase Fenet (1856) Tomo XiII, pp. 453-466. En Halpérin (1996) pp. 101 y ss., se describe el Code como una simbiosis entre la tradición y los nuevos aportes del iusnaturalismo. De hecho, este autor explica que las materias referidas a la propiedad y a los delitos fueron tomadas de los proyectos anteriores redactados por Cambacérès. El tercer proyecto de Cambacérès, de 1104 artículos -que se encuentra más próximo a las ideas
} 
La redacción del proyecto definitivo fue presentada por la Comisión el 19 de ventoso del año XII (19 de marzo de 1804). Particularmente interesante es el artículo 4 del proyecto: "Le Code civil sera en trois libres. Le premier libre será composé des douze premières lois; le second des quatre suivantes; et le troisième des vingt dernières; le tout dans l'ordre qu'elles sont énoncées en l'article $1^{e r}$ ci-dessus". Examinado el proyecto definitivo por el Tribunado, sugirió modificar, entre otras cuestiones, el 22 de ventoso del año XII en el artículo 4 la expresión "le tout dans l'odre qu'elles sont énoncées", por "dans le même ordre". Presentado al Consejo de Estado, este lo adoptaba en similares términos. Según el artículo 1: "Seront réunies en un seul corps de lois, sous le titre de Code civil des Français, les lois qui suivent... ”, enunciando los distintos proyectos publicados. La redacción final del artículo 4 fue como sigue: "Le Code civil será divisé en un titre preliminaire et en trois libres", detallando enseguida en contenido de cada uno de los libros.

El proyecto se presentó al Cuerpo Legislativo el 28 de ventoso del año XII. El 30 de ventoso del año XII (21 de marzo de 1804), el Cuerpo Legislativo sancionó el código definitivo. Finalmente, antes de la publicación del Code, el Gobierno Imperial reemplaza la República, sustituyendo las expresiones Cónsul, República, Nación, por las de Emperador, Imperio, Estado. La edición nueva fue publicada el 22 de agosto de $1807^{11}$.

El Code quedó así estructurado en un título preliminar y tres libros. El título preliminar fue construido siguiendo las ideas de Domat, quien aparentemente siguió, a su vez, las ideas del iusnaturalismo racionalista alemán relativas al establecimiento de una parte general. Los tres libros siguientes obedecen a la partición gayana del Derecho en personas y cosas y estos, a su vez, en corporales e incorporales. Así, el Code originalmente se dividía en un Libro Primero, Des personnes (artículos 7-515), que contenía las materias referidas al estado civil, el matrimonio, entre otras; un Libro Segundo, Des biens et des différentes modifications de la propriété (artículos 516-710), regulaba el régimen de bienes, la propiedad, los derechos reales recaídos sobre bienes de otros y las servidumbres prediales. Por último, el Libro Tercero, Des différentes manières dont on acquiert la propriété (artículos 711-2281), regulaba las sucesiones, las donaciones y testamentos, introducía una regulación general de los contratos, los cuasicontratos, los delitos y cuasidelitos, las relaciones patrimoniales entre cónyuges, los contratos típicos, el fideicomiso, la transacción, la prenda, la anticresis, los privilegios y la hipoteca, de la expropiación forzada y del concurso de acreedores; y, de la prescripción.

La responsabilidad civil se encontraba tratada originalmente en el Libro Tercero, Título IV, bajo el epígrafe "Des engagements qui se forment sans convention" ("De las obliga-

de Pothier-, fue seguido muy de cerca por los redactores, al punto que según Halpérin, cerca de 200 artículos fueron reproducidos en el texto del Code. El artículo 1382 habría sido tomado directamente del tercer proyecto de Cambacérès de 1797. Según Halpérin: "Ces examples pourraient être multipliés, ils démontrent qu'une grande partie du travail de sélection des sources avait été déjà fait par Cambacérès, en se référant souvent a Pothier...”. En un sentido similar y apuntando especialmente al carácter práctico del Code, véase FiLOMUSI (1949) p. 189; FuRET y Ozouf (1989) p. 409, quienes indican que con los trabajos de las comisiones revolucionarias quedaron ya trazadas las grandes líneas del Code.

11 Nuevamente, remitimos en estas materias a la descripción histórica de FENET (1856) Tomo I, pp. lxxxviiixci; xcviii. Para la importancia de Bonaparte en el proceso de preparación del Code, puede consultarse el trabajo de Savatier (1927); y, Carbonier (2004) pp. 20 y ss. 
ciones que se contraen sin convenio"), Capítulo II, bajo el epígrafe "Des délits et des quasidélits" ("De los delitos y cuasidelitos"), artículos 1382-1386. Con todo, debemos tener presente la reciente modificación a la que ha sido sometido el Código civil francés. En efecto, el Ejecutivo francés obtuvo autorización del Parlamento francés para modificar y readecuar el Código en razón de la Ordenanza 2016-131 ${ }^{12}$. Sin alterar su contenido, las normas de los delitos y cuasidelitos, tituladas ahora simplemente como responsabilidad extracontractual y ubicadas entre las fuentes de las obligaciones, se ubican en los artículos 1240 a 1244.

\section{B. La consagración de la culpa (FAUTE) EN El Code}

El Código Napoleón consagró el trinomio (culpa, daño, responsabilidad), en los artículos 1382 y 1383. Según el artículo 1382 (actual artículo 1240): “Tout fait quelconque de l' homme, qui cause a autrui un dommage, oblige celui par la faute duquel il est arrivé, à le réparer" "Todo hecho del hombre que causa a otro un daño, obliga a aquel por cuya culpa ocurrió a repararlo"). Por su parte, el artículo 1383 (actual artículo 1241) del mismo Código señala: "Chacun est responsable du dommage qu' il a causé non seulement para sont fait, mais encore par sa négligence ou par son imprudence" ("Cada uno es responsable del daño que ha causado no solo deliberadamente, sino también por su negligencia o imprudencia”).

Según la opinión tradicional, el artículo 1382 se refiere al delito civil, es decir, al daño causado con culpa intencional o dolo. La palabra hecho que emplea el precepto, designa el hecho ilícito, es decir, la culpa intencional. En tanto, el artículo 1383 se refiere a la culpa no intencional y menciona tanto a la negligencia como la imprudencia. Además, existen en el Código Civil francés disposiciones complementarias de la regla general, contenidas en los artículos 1384 a 1386 (artículos 1242 a 1244 de acuerdo a la reforma). En la explicación tradicional, estos artículos constituyen presunciones de culpa destinadas a facilitar el ejercicio de la acción de reparación y tienen su origen en la jurisprudencia antigua francesa.

Hecha esta breve genealogía de las reglas de responsabilidad civil en el Código civil francés, revisaremos la lectura tradicional que se hace de las normas de responsabilidad civil aquilianas contenidas en dicho código, el papel que en ellas cumple la culpa y el rol de Domat, como fuente inspiradora de una cláusula general fundada exclusivamente en la culpa.

\section{LA TESIS TRADICIONAL SOBRE EL FUNDAMENTO DE LA RESPONSABILIDAD CIVIL}

\section{A. El carácter simbiótico del Code: una estructura compleja}

De acuerdo con nuestro juicio, Ewald lleva razón cuando advierte que el Code es una obra institucionalista y de corte conservadora, que pone a la familia en el centro de

\footnotetext{
12 Véase Ley 17-2015, 16 de febrero y la Ordenanza 2016-131, de 16 de febrero. Tanto las referidas normas, como el texto definitivo, puede consultarse en www.legifrance.gouv.fr. Sobre la materia, véase también MoMBERG (2015) pp. 121 y ss.
} 
la regulación de la sociedad ${ }^{13}$, como demuestra claramente el último pasaje del discurso preliminar: "Tales son las bases principales de las que hemos partido en la redacción del proyecto de Código civil. Nuestro objeto ha sido ligar las costumbres a las leyes y propagar el espíritu de la familia, que es tan favorable, se diga lo que se diga, al espíritu de la ciudad. Los sentimientos se debilitan al generalizarse: es necesario un asidero natural para poder formar lazos de conveniencia. Las virtudes privadas pueden ellas solas garantizar las virtudes públicas; y es por la pequeña patria, que es la familia, por la que uno adhiere a la grande; son los buenos padres, los buenos maridos, los buenos hijos los que forman los buenos ciudadanos" 14 .

Pero el carácter conservador en materias de familia no puede negar que los redactores estén marcados por las ideas iusnaturalistas, que atraviesan todo el discurso preliminar de Portalis ${ }^{15}$. En casi todas las materias a las que se refiere Portalis en su discurso, hay una referencia a reglas o principios básicos del Derecho natural, entendidos desde la recta razón del hombre. No se trata, a nuestro juicio, de un Derecho natural fundado en una metafísica religiosa, sino que, en un iusnaturalismo racionalista y laico, aunque a menudo este esconda muchas de las ideas conservadoras de la época. Desde luego, ello no importa el abandono de las instituciones del Derecho romano, releídas ahora bajo la luz de las nuevas ideas ${ }^{16}$.

Puede afirmarse, sin duda alguna que todo el proceso codificador utilizó los materiales del Derecho romano, de los autores del Derecho común y de la segunda escolástica, de modo que la codificación y, desde luego, el Código civil francés se presentó como una simbiosis entre la continuidad y ruptura ${ }^{17}$. Es por esta razón que puede considerarse el Code como un texto ecléctico y flexible, que utilizó materiales del Derecho romano en múltiples materias, pero en otras se pronunció expresamente contra las soluciones de dicho sistema, acercándose a las costumbres jurídicas francesas. Tampoco debe perderse de vista que la aproximación a las fuentes del antiguo Derecho, al menos en el terreno que analizamos, proviene desde las lecturas iusnaturalistas, de modo que en concretas materias se refleja el aporte de estos, como ocurre con la transferencia de la propiedad por el solo vínculo con-

13 Según el autor, el objetivo político del Code es estabilizar la sociedad francesa, especialmente a través de la familia. Desde este punto de vista, la propiedad no es el paradigma del individualismo, sino que, por el contrario, una institución social, limitada de acuerdo al bien común. En la base de Code está la idea de imprimir un carácter duradero a su regulación, cumpliendo así un papel de despolitización que permite hablar de libertad. Véase EWALD (2004) pp. 93-95.

14 Portalis (1997) p. 108.

15 Más dudoso es si puede considerarse al Código como una obra liberal. Para Caroni, por ejemplo, puede ponerse en duda el lugar asignado al Code, como obra jurídica liberal, fundada en el principio de la autonomía privada. Según él, la capacidad jurídica otorgada por la regulación burguesa y junto con ella el principio de igualdad y la libertad de contratación, se otorga solo en miras a un uso conforme al sistema económico dominante. No cualquier uso de las libertades, sino aquel que permita un uso valorizante. Desde esta premisa, piensa que las normas del Código pueden leerse como un instrumento de disciplina social, que desincentiva un uso irracional y parasitario de los derechos. Véase CARONI (1996) pp. 39-52 y 84-86.

16 Desafortunadamente, no se refiere Portalis en parte alguna de su discurso a las materias relativas a la responsabilidad aquiliana. En el mismo sentido, GordLey (1994) p. 479.

17 Para esta cuestión véase, por todos Halpérin (2004) pp. 46-53 y antes en Halpérin (1996) pp. 101 y ss., Filomusi (1949) p. 189; Furet y Ozouf (1989) p. 409. 
tractual (tomado desde las ideas de Grocio y Pufendorf, pero contra Pothier) y la responsabilidad por faute.

Concretamente sobre el tema que analizamos, Auzhary-Schmaltz indica que durante los siglos XII y XIV llegó a distinguirse perfectamente, en el Derecho francés y en la jurisprudencia real, entre la sanción penal y la responsabilidad civil (distinguiendo, a su vez, entre la delictual y la contractual). El mecanismo que impulsó dicho cambio fue la sustitución de la pena por el mecanismo de la pax privata (la indemnización), que situaba el problema de la composición en los intereses privados ${ }^{18}$. En cuanto al concepto de reparación, este fue especialmente desarrollado por la doctrina canonista de la segunda escolástica española, que terminó influyendo decisivamente en la obra de Grocio. En efecto, la ampliación se produjo especialmente por el influjo de los canonistas, quienes aportarán el concepto de restitución, de modo que lo fundamental en la interpretación de la lex Aquilia se tradujo en poner las cosas en el estado anterior al daño, haciendo desaparecer los efectos de este ${ }^{19}$.

\section{B. LA CULPA COMO FUNDAMENTO DE LA RESPONSABILIDAD CIVIL}

Según el punto de vista tradicional, seguido por una gran mayoría de autores, que por cierto llega a ser un lugar común, los redactores de los códigos civiles decimonónicos dieron a la responsabilidad civil una estructura de carácter netamente individualista ${ }^{20}$. Los factores de dicha concepción son múltiples y variados. En principio, la obligación de resarcir perjuicios parecía una consecuencia natural de la calificación del hecho como algo reprobable. A ello debemos sumar el desarrollo de una economía basada, hasta ese momento, en relaciones interindividuales y en la igualdad de los sujetos ${ }^{21}$.

El predominio de la escuela iusnaturalista y de la filosofía liberal, que toma al individuo como eje central de todas las valoraciones sociales, descarta la condena económica de un individuo, cuando el daño no ha sido fruto de su libre actuación. Así, la codificación se fundaría, siguiendo la doctrina de la escuela del Derecho Natural racionalista, en el dogma de la autonomía de la voluntad. Este principio de naturaleza u origen filosófico sirve de fundamento para toda la regulación patrimonial del derecho codificado, tanto civil como comercial. Cuando decimos que la voluntad crea derechos y obligaciones, implica que la

\footnotetext{
18 Auzhary-Schmaltz (1999) pp. 165-168; 180. Sin duda alguna, el mecanismo francés tiene precedentes en el Derecho romano. Al respecto, véase nuestro trabajo Aedo (2009) pp. 23 y ss.; y, Aedo (2011) pp. 1 y ss. Como señala Albanese, la obra jurisprudencial fue particularmente incisiva sobre todo en orden a cuatro perfiles en relación con los capítulos primero y tercero de la ley: a) superación de los límites impuestos por los verbos usados para describir la actividad dañosa: occidere, en el capítulo primero; urere, frangere, rumpere, en el tercero; b) desarrollo de una vasta perspectiva de responsabilidad, predicada en términos de iniuria hasta la refinada perspectiva de la culpa; c) paso de una aestimatio fundada sobre el precio de mercado del objeto del daño y de una valoración coincidente, a veces, con el interés subjetivo del dañado; d) extensión del resarcimiento del daño a sujetos distintos del propietario. Véase AlbANese (1992) p. 43.

19 Véase Bussi (1937) pp. 197-200.

20 La perspectiva clásica entiende que el Código es un producto de la sociedad burguesa, cuyas notas fundamentales son el laicisismo y la individualidad. Sobre esta cuestión, véase especialmente Duguit (1920) pp. 13 y ss. Le sigue, Gómez (1951) pp. 499-502; y, Corradini (1971) pp. 37-48.

21 Véase, por todos, VINEY (1998) p. 18 y en su trabajo VINEY (2004) pp. 256; 266-267.
} 
voluntad es autónoma y se basta a sí misma ${ }^{22}$. De esta manera, el derecho codificado clásico se estructura mediante la consagración constitucional de la libertad contractual y la regulación practica a nivel del código de la autonomía de la voluntad y de la libertad contractual; su corolario es el rol restrictivo del Estado; que se limitara a garantizar la eficacia del contrato y sancionar el fraude. Como indica Arnaud, libertad y propiedad están en la base o son pilares del Code. La libertad, como concepto económico, se traducía en el concepto jurídico de la libertad contractual y en un estadio más evolucionado, en el principio de la autonomía de la voluntad. Dichas expresiones suponían relaciones contractuales libremente consentidas entre hombres iguales ${ }^{23}$.

Concretamente, en el ámbito de la responsabilidad, los hermanos Mazeaud sostienen que, en esta materia, los redactores del Code se contentaron con copiar a Domat. Agregan: "Los artículos 1382 a 1386, inscritos en el capítulo "De los delitos y de los cuasidelitos", reiteran el principio general de responsabilidad civil expuesto por Domat, al mismo tiempo que precisan el requisito fundamental de la responsabilidad: la culpa; culpa intencional (que denominan "hecho": artículo 1382); o culpa por imprudencia o negligencia (artículo 1383)" "24. Los artículos 1384-1386 serían una aplicación de la regla general consagrada en los artículos 1382-138325.

De este modo, siguiendo a Mazeaud y Tunc ${ }^{26}$, las ideas de Domat, incorporadas al Code, pueden resumirse en las siguientes: los redactores se mostraron unánimes al afirmar la necesidad de una culpa para exigir la responsabilidad del autor del daño. La idea es reiterada por todos los redactores del Código. Así, por ejemplo, Treilhard, en la exposición de motivos, declara: "Regulada así, la responsabilidad es totalmente justa. Aquellos a los que se le impone han de imputarse, al menos, unos, debilidad, otros la mala elección, y negligencia todos". La segunda idea que inspiró a los codificadores consiste en que, exigiendo culpa para imputar responsabilidad, basta cualquier culpa; no se requiere que el autor del daño haya tenido la voluntad de causar ese daño. En tanto el hombre es libre, debe responder de las consecuencias disvaliosas de sus actos. Este es un esquema lógico normativo incorporado a todas las legislaciones decimonónicas ${ }^{27}$. En suma, como enseña Savatier, la culpa se presentó como el corolario de la libertad de los individuos ${ }^{28}$.

En otros términos, la culpa se propone como una especie de pecado jurídico y como la causa del deber de reparar el mal causado, ya que el que incurre en ella, ha actuado mal. El hombre debe responder de las consecuencias de sus acciones humanas, no de aque-

\footnotetext{
22 En este sentido, Caroni (1996) p. 83 y Arnaud (1969) pp. 197-209; 260.

23 Arnaud (1969) p. 178. Como afirma Halpérin (2004) p. 53, si bien es cierto hay materias en las que puede denotarse el autoritarismo napoleónico, especialmente en familia, el lenguaje del Código y buena parte de sus normas de corte liberal, revolucionario.

24 Mazeaud et al. (1978) p. 16. No obstante, como advierte Auzhary-Schmaltz (1999) p. 183, las antiguas costumbres francesas y los juristas franceses del medioevo, por influencia del Derecho romano, ya tenían bastante desarrollada la idea que toda injuria merecía una reparación o satisfacción.

25 En este sentido, Viney (1998) p. 19.

26 Mazeaud y Tunc (1977) pp. 60-62.

27 Urbano (1996) p. 279.

28 SAVATIER (1959) p. 6.
} 
llas que tienen el carácter de infortunio ${ }^{29}$. La idea de la faute impregnada de moralidad es un lugar común entre los autores franceses ${ }^{30}$. Sobre el punto, Viney, quien cita la opinión de Tarrible: "S'agit-il de dommages causés? Ce projet épuise touts le moyens d'une assurer la réparation; et dans le nombre de ces moyens, il place une responsabilité morale qui doit redoubler la vigilance des hommes chargés du dépôt sacré de l'autorité et qui préviendra ainsi plus de désordres qu' elle n' en aura à réparer". Sostiene la autora que dicha moral fue recogida por Domat desde los canonistas y el antiguo derecho francés, colocando como eje de ella la fau$t e^{31}$.

En el apartado siguiente examinaremos los argumentos que, a nuestro juicio, permiten cuestionar la perspectiva tradicional antes referida, en el sentido que las normas del Código civil no se fundaron en Domat para el tratamiento de la falta, porque el autor francés se separa de la codificación en su fundamento filosófico, en su perspectiva antropológica y en el tratamiento mismo que otorga a la materia de responsabilidad civil. Estas distintas perspectivas permitirán abonar a favor de la hipótesis que se sostiene en este artículo, lo que tiene un indudable fin práctico en la reconstrucción de la historia de la culpa. Si esta (la faute) no responde a las particulares ideas éticas de Domat, no puede seguirse pensando que la codificación consagró un modelo de culpa moral, distinto del sentido jurídico proporcionado en el Derecho romano.

\section{NUESTRA POSICIÓN: EL CODE NO SIGUIÓ LAS IDEAS DE DOMAT EN MATERIA DE FAUTE}

\section{A. El argumento de método: El pensamiento jurídico-filosófico de Domat}

La afirmación según la cual la culpa en el Code se concibió como un pecado jurídico, es decir, equivalente a la moral católica, no concuerda con el desarrollo del pensamiento jurídico de la época, en cuyo ambiente terminaron primando las ideas iusnaturalistas racionalistas $^{32}$.

Por su parte, el pensamiento de Domat se estructura, como explica Sarzotti, entre perspectivas confrontadas. Hay en la obra de Domat una dialéctica entre el laicismo propio del iusnaturalismo y la trascendencia del pensamiento cristiano; entre el individualismo jurídico, al que se llega a través del método analítico-sintético, el espíritu y la mirada cristiana del hombre. Como afirma el autor que seguimos, Domat intenta conciliar estos dos mundos; de un lado, adopta el pensamiento racionalista y empírico del mundo desarrolla-

\footnotetext{
29 Ripert y Boulanger (1965) p. 23.

30 Según Mazeaud y Tunc (1977) p. 51, nota 3bis, en la tesis doctoral de Yves Ranjard, titulada La responsabilité civiles dans Domat, de 1943, se ha mostrado que, en materia de responsabilidad civil, los guías de Domat han sido los Evangelios y el Derecho romano. Y, por su parte AuZHarY-Schmaltz (1999) p. 189 indica que la idea de una regla general fundada en la culpa, se ancló en la moral de los canonistas, seguida después por los iusnaturalistas.

31 Viney (1998) pp. 18-19. En igual sentido, Poughon (1992) p. 104; Gilles (2009) pp. 28-29; DesCAmpS (2008) pp. 23 y 26.

32 Precisamente, teñir la faute de la moralidad católica o escolástica no concuerda con las fuentes romanas cristianas reflejadas en la obra de Justiniano. Véase BIONDI (1954) pp. 261 y ss.
} 
do en su época, pero considera que en el mundo existe una dimensión trascendente: el Derecho, para ser tal, debe corresponderse con el orden dado por Dios ${ }^{33}$.

De este modo, Domat no puede ser considerado, en estricto rigor, como un representante de la Escuela del Derecho Natural de su época, pues si bien es cierto se sirve de los métodos cartesianos, buscó, como se ha advertido, un fundamento trascendente para el Derecho, de base cristiana ${ }^{34}$. La influencia del método cartesiano se tradujo en los afanes de Domat. La finalidad del jurista francés fue ordenar sistemáticamente el ius civile, para remediar el desorden que había experimentado como magistrado, comprendiendo todo el Derecho: el Corpus Iuris justinianeo y las normas derivadas de las costumbres francesas, procediendo a una sistematización de base racional, entendiendo por esta la lógica deducti$\mathrm{va}^{35}$.

Domat buscaba, en definitiva, una fundamentación trascendente para el Derecho ${ }^{36}$. Siguiendo a Tale, en el pensamiento filosófico jurídico del autor francés, el Derecho puede ser separado en Derecho natural y positivo. Las reglas de la ley natural mueven espíritu y razón y por ello persuaden al hombre antes que las verdades científicas y, aun cuando son reglas que se encuentran insertas en el espíritu humano y pueden ser deducidas por la razón, los hechos muestran que los pueblos que estuvieron fuera de la religión cristiana se alejaron de la esfera de estos principios en algunos $\operatorname{casos}^{37}$. En un sentido similar, Todescan indica que, a diferencia del racionalismo, Domat entiende que los primeros principios se captan con el corazón y no solo con el espíritu, como en el caso de la ciencia ${ }^{38}$.

\footnotetext{
33 Sarzotti (1995) pp. 6-20. Gilles (2009) p. 8, señala: "La pensé de Domat se rapproche de celle d'un Pufendorf ou d'un Wolff quant a sa structure geométrique. Sa réflexion sur les fondaments du droit, qu'elle qu'en soit la pesanteur scolastique, ne cesse de subir l'attraction des sciences physiques et mathématiques, sous la forme essentiellement d'une dynamique euclidienne partant d'un certain nombre de définitions, d'axiomes et de príncipes afin de démontrer un ensemble de propositions ou de théoèmes". Véase también Renoux-ZaGamé (1993) p. 52.

34 El iusnaturalismo racionalista se distingue de las formulaciones medievales, no por la construcción de un Derecho fundado en la razón humana, pues el tomismo también funda dicho Derecho innato al hombre en la razón, sino en lo que Welzel denomina la secularización del Derecho. Como explica este autor, el concepto de ratio va a sufrir una transformación. Mientras en la filosofía aristotélica y por tanto tomista, la racionalidad del hombre equivalía al hombre social y político, es decir, suponía que el hombre era un ser destinado por naturaleza a vivir en comunidad y solo en razón de eso el obrar racional constituía una regla fundamental; en cambio, esta base metafísica teológica desaparece ahora y la ratio constituye por sí misma la fuente del conocimiento. Véase Welzel (1977) pp. 175 y ss.

35 Véase en este sentido, Matteucci (1959) pp. 48-49. También Ghestin (1994) Tomo I, pp. 540-543. Gilles (2009) p. 8, Domat será el primer jurista que, frente a la proliferación normativa, fuente de inseguridades y confusión, va a proponer una sistematización geométrica del Derecho, de base racionalista. Y RenOuX-ZaGAMÉ (2004) p. 38, indica que, a la época de Domat, la Biblia guía y alimenta la reflexión de los hombres de justicia, que encuentran, a su vez, reflejo en las reglas del Derecho romano y en los textos de filosofía y literatura. Para Domat, igualmente, hay cierta convergencia entre el Derecho romano y los preceptos bíblicos.

36 Gilles (2009) p. 9.

37 Tale (1997) pp. 292-293. Como indica Renoux-Zagamé (1993) pp. 50; 55, Domat conduce a la codificación dentro de la potente tradición agustiniana de la mayoría de los pensadores cristianos, que son conducidos a pensar que la autoridad pública debe establecer reglas para evitar la perversión de los hombres. De este modo, agrega, Dios no solo hace de Dios el origen del poder spiritual, sino del poder terrenal.

38 TODESCAN (2014) p. 158: "Ma i primi principi ogni nomo debe scoprirli nel fondo del proprio cuore, nella lettura dell'inclinazione di tutto il proprio essere verso l'Assoluto. In particolare, per il giansenista Domat, i principi primi
} 
Como indica Sarzotti, debe tenerse en cuenta que Domat es un pensador profundamente cristiano y, en cuanto tal, sus ideas se fundan en el presupuesto de la correspondencia entre el orden mundano del universo y la creación. Su metafísica, en definitiva, establecida sobre la base de la filosofía aristotélico-tomista, constituye una reacción a la laización del pensamiento europeo ${ }^{39}$. De esta manera, advierte Sarzotti, el Derecho viene reducido a sistema, concebido como un conjunto axiomático de reglas que pueden ser elaboradas a partir algunos principios inmutables, a través del uso de la lógica deductiva y silogística ${ }^{40}$. Desde los principios del amor a Dios y el amor al prójimo es posible construir, por vía deductiva, todo el sistema de las leyes del hombre. Aunque Domat no se contenta solo con este método, pues en su opinión no es posible alcanzar el conocimiento de los primeros principios solo con la lógica deductiva, de ahí que recurra al método analítico-sintético de estudio de la naturaleza humana, adoptado de Galileo y Descartes. Ello importa que, separándose del Derecho romano, abandone la tripartición gayana de persona-cosa-obligaciones y adopte la división entre engagements y successions ${ }^{41}$.

Desde el punto de vista del método de Domat, la perspectiva tradicional puede ser cuestionada. Una primera objeción tiene un indudable carácter interno, pues deriva a nuestro juicio de la incompatibilidad de ideas con la que los autores abordan la cuestión. Y así ocurre que mientras se afirma el carácter individualista de las reglas de la responsabilidad civil, junto con ello se estima que la moral domatiana tiñe la consagración de la culpa. Ambos puntos de vista son inconciliables. La Ilustración, como ha dicho Hazard, pretende, entre otras cosas, abatir el cristianismo, abriéndole un proceso, derribando todo prejuicio religioso $^{42}$. Aun así, debemos advertir que en Francia el espíritu burgués del capitalismo estaba unido a la tradición protestante del calvinismo y del jansenismo. En ambos se plantea la lucha contra el desorden y la implementación de un orden institucional al que debían sujetarse las personas ${ }^{43}$, pero con una desconfianza radical en la luz de la razón humana, corrompida por el pecado original ${ }^{44}$.

di diritto si possono scoprire in due modi, con l'esprit e con il coeur: è questa una differenza rilevante rispetto ai principi delle altre scienze, che vengono manifestati solo dall'esprit".

39 SARzotTi (1995) pp. 9-10. Aunque discurren sobre otros derroteros, particularmente sobre la genealogía de las reglas de interpretación del Código civil chileno, ajenos a nuestro trabajo, véase GUZMÁn Brito (2004) pp. 43-45. Cfr. con la posición, contraria a Guzmán, en cuanto considera que no puede afirmarse la genealogía de las reglas de interpretación hasta Domat, BASCuñán (2013) pp. 321 y ss.

40 En este sentido, Gilles (2009) p. 10. También Renoux-Zagamé (1993) p. 58; Renoux-Zagamé (2004) p. 37. Afirma TODESCAN (2014) p. 157: "Era questo un camino verso cui Domat veniva indirizzato in parte dal suo stesso giansenismo, col resudiante deduttivismo di stampo cartesiano, utile a dare una pronfonda sistemazione al vastissimo materiale normativo, senza privilegiare questo o quel genere di fonti, in singolare analogía, com'è stato osservato, col programa leibniziano di "mesa in ordine razionale» dell'interno diritto vigente".

41 Sarzotti (1995) pp. 48-49. Véase también Auzhary-Schmaltz (1999) p. 182. Como indica Gilles (2009) pp. 14-15, los engagements son entendidos como los efectos del amor sincero que todo hombre debe a todos los otros. Distingue así, Domat, desde el amor a los hombre, entre engagements propios de la familia y aquellos no familiares, entre los que distinguirá, a su vez, entre actos voluntarios e involuntarios.

42 Hazard (1963) p. 38.

43 Véase, en este sentido, Martínez (2000) pp. 92-93.

44 Es reconocido en la doctrina que la corriente del iusnaturalismo racionalista fue fundamentalmente una corriente de cuño protestante, que vino a reaccionar a los postulados filosóficos y la cultura escolástica anterior. 
Desde otra perspectiva, siguiendo a Sarzotti, el método de Domat, precisamente por las influencias pascalianas y jansenistas, se diferencia del iusnaturalismo de base racional. Particularmente interesa destacar que el jansenismo, traducido en la fundamentación cristiana del Derecho, importa en Domat el abandono de cualquier idea secularizadora y contractualista de las relaciones humanas. Apreciada ahora la cuestión en comparación con la filosofía aristotélico-tomista, Domat efectivamente diferencia entre una esfera interna, en la que se desarrolla el concepto del ámbito privado y una esfera externa, relativa a la vida pública y social del individuo, derivada del contractualismo político. Esta escisión, que representa una separación más general de las esferas política y moral, viene releída en la obra domatiana. El hecho que no ignore esta diferenciación, revela su modernidad, pero la circunstancia de no abandonarse a una radical separación de estos dos ámbitos demuestra cómo en su pensamiento no puede ser asimilado al moderno contractualismo. La antropología domatiana, concibiendo la dimensión moral y la política del hombre del modo unitario, representa la reacción cristiana al proceso de secularización del iusnaturalismo. En cuanto concibe al individuo como un ser totalmente social, Domat no puede separar una esfera pública del individuo, en el cual pueda ser pensado como un ciudadano que con su voluntad funda el pacto social, liberado de consideraciones morales e inspirado solamente en su instinto de conservación ${ }^{45}$.

Dado que los redactores, como ha demostrado Arnaud, incorporaron en el Code los ideales del iusnaturalismo racionalista, apartándose por consiguiente del método de Domat, siguiendo el esquema de las Instituciones de Justiniano, es difícil pensar en la incorporación de las perspectivas jansenistas de este.

Precisamente, si nos centramos en los poquísimos datos que nos han dejado los redactores - pues el discurso preliminar omite mencionar la cuestión de la responsabilidad civil- las conclusiones nos alejan de la tesis mayoritaria. Por ejemplo, a propósito de la espinosa cuestión del divorcio, Portalis se plantea las siguientes interrogantes: “¿Hay una religión dominante? ¿Cuáles son los dogmas de esta religión? O bien, ¿todos los cultos están indistintamente autorizados? ¿Estamos ante una sociedad incipiente o frente a una sociedad ya madura?”. Según Portalis, solo una razón formada alcanza la regulación del matrimonio según las leyes naturales, que o bien proscribe el divorcio o lo limitan, según las costumbres de cada pueblo, pero enseguida señala que dicha materia no puede quedar regulada según la moral católica, porque, argumenta, en Francia la libertad de cultos es una ley fundamental y la mayoría de las doctrinas religiosas autorizan el divorcio y agrega: "Los ciudadanos pueden profesar diversas religiones; pero se necesitan leyes para todos (...) Hemos creído que no se debía prohibir el divorcio entre nosotros, porque nuestras leyes estarían demasiado formalmente en contradicción con los diferentes cultos que lo autorizan, y porque no

En este sentido, in extenso, CARPINTERo (2000) pp. 170-175. Sobre el punto, véase también a PaSSERIN (1965) pp. 80-94.

45 SARZOTTI (1995) pp. 242-243. Como indica TODESCAN (2014) p. 169: "É la temática agostiniana cara a tutti i giansenisti, in particolare Pascal, che qui risuona: la natura umana aspira con tutte le sue forze alla felicità, ma questa, sulla terra, è del tutto irraggiungibile da parte della creatura umana". In extenso, sobre la libertad, el papel de la gracia en el jansenismo y la corrupción por el pecado, el mismo ToDESCAN (2014) pp. 173-176; 199-200. 
podrían esperar hacer el matrimonio, para los hombres que profesan esos cultos, un vínculo más fuerte que la religión misma” ${ }^{36}$.

Si en una materia de tanta sensibilidad moral Portalis se aparta del pensamiento de la religión a la que pertenece, para asumir un enfoque racionalista $-\mathrm{y}$ hasta pactista, contractualista podríamos decir-, ¿por qué deberíamos asumir en el campo de la responsabilidad extracontractual su enfoque sería el de una jurista que, aun cuando inspirando parte de sus disposiciones, pertenecía a un sector minoritario de la Iglesia Católica? En otras palabras, todos los iusnaturalistas racionalistas se referían a la moral, pero ahora apoyada en la razón del hombre, como se hace mención en varios pasajes del discurso preliminar de Portalis.

Visto así el problema, puede pensarse que las referencias a una culpa (faute) teñida de la moral cristiana propia del autor francés corresponde a una relectura de la dogmática posterior al Code, que pretende cierta desvalorización del papel de la culpa, como inadecuada para el momento en que las relaciones sociales se habían complejizado. Sobre todo, una lectura de este tipo arranca desde una perspectiva idealista y racionalista, de base kantiana del Derecho, que se traduce en una rígida separación entre las esferas privada y pública, difícilmente comunicables con las ideas de Domat.

Por otro lado, una aproximación tradicional a la culpa nos parece que constituye una petición de principios y, por tanto, falsa: ¿qué se quiere decir exactamente cuando se afirma que la faute consagrada en el Code estaba "teñida de moral"? La cuestión, a nuestro modo de ver, es otra, ¿es reconocible un sistema de responsabilidad sin un fundamento moral? Ciertamente, la circunstancia que a nuestro juicio no se haya seguido a Domat en estas materias no representa obstáculo alguno para considerar que, en efecto, la culpa jurídica obedece, como la responsabilidad estricta, a un fundamento moral propio de la responsabilidad civil. Que estén ausentes los presupuestos filosóficos, éticos y sobre todo antropológicos de Domat en esta materia, no implica que los redactores o, planteado de manera más general, el pensamiento racionalista no se mueva en la idea de la moral en un sentido determinado.

\section{B. La Perspectiva antropológica del Code Versus la de Domat}

El pesimismo de la naturaleza humana que sustenta el jansenismo y, por consiguiente, la perspectiva de Domat, podría hacernos considerar que el pesimismo de la naturaleza humana que aparece en el Code recoge, al menos en la materia que analizamos, la visión de Domat. Sin embargo, como veremos, este juicio tampoco puede ser aceptado. Al margen de la excesiva simplificación que envuelve, debe rechazarse por dos razones. En primer lugar, porque Domat no sigue íntegramente la visión jansenista, de la corrupción de la razón humana: esta puede alcanzar el conocimiento de los primeros principios, por una intuición racional (no solo por la gracia), fundando por tanto en la razón y, en definitiva, el Derecho,

46 Portalis (1997) pp. 63-66. 
en Dios (contrariamente al secularismo), lo que nos indica que Domat tiene una cierta visión positiva y comunitaria del hombre, como ser esencialmente sociable ${ }^{47}$.

En segundo término, porque de tener el Code en particular una visión pesimista, esta encuentra otras raíces. En efecto, Halpérin, por ejemplo, sostiene que el juicio pesimista de la naturaleza humana deriva de la escuela sensualista de Condillac, que postula la utilización de la coacción jurídica, especialmente de la familia, para reconstruir la sociedad y la propiedad como un medio de asegurar al hombre el orden social. En cuanto a la ideología, sustentada principalmente por Portalis, un juicio crítico a la revolución francesa y a las ideas de estado de naturaleza de Rousseau, es sustituida por la visión de una sociedad que no emana de un pacto, sino de los hechos, en la que ocupa un gran lugar la familia. Aun así, señala que Portalis es alimentado tanto por Locke, como por Montesquieu, quien además conocería a autores iluministas como Mandeville, Smith o Fergurson, de modo que Halpérin entiende que Portalis recibió influencias en ambos sentidos, es decir, tanto liberales, como contrarrevolucionarias ${ }^{48}$.

Por su parte, Martin ha argumentado que la visión pesimista de la naturaleza humana contenida en el Code encaja perfectamente con el pensamiento hobbesiano. El punto de partida de toda su argumentación se sitúa en las suspicacias de la regulación del Code al altruismo humano, traducida, por ejemplo, en las trabas que dicha legislación pone a las donaciones. Martin cree que en caso alguno se adoptó la visión de los revolucionarios, por cuanto según ellos el hombre es naturalmente bueno, siendo el estado de naturaleza paradisiaco, idea que encuentra su fuente en Rousseau. Así, la generación de 1789-1792 buscó purgar las costumbres, que obscurecían la naturaleza del hombre. Por el contrario, los codificadores habrían roto con el mito del hombre bueno, de la bondad natural del hombre y habrían sostenido que el alma humana estaba contenida de un egoísmo y debilidad constantes ${ }^{49}$.

La lectura de los codificadores correspondería a las ideas hobbesianas, según este autor: para asegurar la propiedad individual y el orden social, es necesario que los hombres pacten, cuya consagración aparecería especialmente en materia de autonomía de la voluntad: esta es la proyección de las inclinaciones o intereses, de ninguna manera es una determinación mental perdurable. Es la ordenación pacífica de las relaciones entre los sujetos y no su naturaleza bondadosa, la que impone el respeto de las convenciones como si estas fuesen una ley para ellas ${ }^{50}$.

En suma, no existen evidencias que permitan afirmar que la visión antropológica de Domat fuese la misma adoptada por los codificadores y que ella se trasladara a las normas

47 Sarzotti (1995) pp. 14-15. Véase también, en el mismo sentido, Tale (1997) pp. 300-303 y RenouxZAGAMÉ (2004) pp. 45 y ss.

48 Halpérin (1996) pp. 108-113.

49 Martin (1982) pp. 594; 599-603. Debemos tener en cuenta, siguiendo a Ricoeur (2005) pp. 18-19, fueron precisamente los autores del Derecho natural quienes se opusieron a las ideas de Hobbes, en el sentido que el hombre estuviese atado por un pacto previo, movido por el temor, desde donde deriva su visión pesimista del hombre. Luego, si asumimos que el Code fue un código iusnaturalista, es difícil aceptar una perspectiva pesimista de la naturaleza humana y menos la visión hobbesiana, como sugiere Martin.

50 Martin (1982) pp. 605-615. 
del Código civil francés. Si este presenta una visión pesimista de la naturaleza humana, en caso alguno se puede considerar que fue la propia del jansenismo, en todo caso, superada por Domat.

\section{La obra de Domat comparada con el Code}

Centrémonos ahora en la obra de Domat y comparémosla con la codificación. A nuestro juicio, hay buenas razones para pensar que tampoco se siguió la doctrina del autor francés, en cuanto al contenido de la faute.

En principio, como hemos advertido, resulta importante destacar que en francés no fue incorporada la expresión latina culpa, sino que, por el contrario, de Domat se tomó la expresión faute $e^{51}$. En su sentido ordinario, es decir, en el lenguaje común, la expresión faute contiene un fuerte componente moral, pues se refiere a toda contravención o daño intencional y, en este sentido, equivale al pecado. En consecuencia, la mejor prueba del pensamiento moral jansenista de Domat es que haya utilizado el término como equivalente de la culpa estricta, en otros términos, de la negligencia, de la imprudencia o de la impericia ${ }^{52}$.

Hay dos posibles explicaciones para estimar que los redactores, habiendo adoptado la expresión faute le asignaron un contenido distinto que Domat. Una primera explicación proviene de la interpretación tradicional que la doctrina ha hecho de los artículos 1382 y 1383. Como se sabe, aunque el Code distinguía entre delitos y cuasidelitos, no es claro que dichas categorías se identificaran con el dolo y la culpa estricta, respectivamente, como hace Pothier ${ }^{53}$. En efecto, el artículo 1370, inciso final, menciona a los delitos y cuasidelitos entre las obligaciones que se contraen sin convención, pero sin definirlos. En lo tocante al Capítulo II, aunque se titula de los delitos y cuasidelitos, tampoco los define, pues el

51 Véase, en este sentido, Cornu (2005) p. 396. Como indica Martínez (2008) p. 276, es difícil establecer las razones por las cuales la palabra culpa no fue admitida en lengua francesa. Por el contrario, sí se admitió tardíamente, hacia el año 1835, en el léxico francés, la expresión culpabilité, como se afirma en JACQUEMET (1952) p. 359 , pero en tal caso solo se empleaba en un sentido muy amplio, para referirse al carácter o estado de una persona que cometía una falta o un daño y, en términos teológicos, al pecado. El Código civil chileno no emplea la expresión culpa en las reglas de responsabilidad extracontractual. El artículo 2284 utiliza el adjetivo culpable, pero en sentido de culpabilidad, porque indica que constituye cuasidelito cuando se hace sin la intención de dañar. Así, el artículo 2314, como los artículos 2317, 2319, 2321. Solo tratándose de los daños a las cosas, el Código emplea la expresión culpa en sentido estricto, como en el artículo 2326 (aunque no menciona el dolo), artículo 2328 (distingue entre culpa y mala intención). En el artículo 2329, finalmente, nuevamente encontramos la distinción entre malicia y negligencia, empleada en el sentido de culpa estricta (por mucho que los numerales se refieran a la imprudencia). De modo que para el empleo de la expresión culpa, hay que remitirse a las definiciones, particularmente al artículo 44, que hace sinónimas las expresiones culpa, negligencia y descuido.

52 Véase LotTin (1954) p. 472. Así lo señala el mismo autor: "La faute morale, étant un acte humain, implique donc nécessairement un acte de raison pratique qui ordonne l'acte vers une fin concréte et un acte de volonté qui y pousse por l'intention. Cette intention, on l'a suffisamment dit au cours de tout l'ouvrage, est ce qui définit formallement l'acte humain et donc l'acte du péché; mais cet acte marque une déviation vis-à-vis de la fin dernière de notre nature rationnelle".

53 Como afirma Viney (2004) p. 255, los artículos 1382 a 1386 presentan un carácter extremadamente breve, general y abstracto. Precisamente es su laconismo el que abandonó a los tribunales de justicia franceses la solución de innumerables cuestiones relativas a la responsabilidad. De hecho, considera que una de las primeras cuestiones que debería ser modificadas, en una posible recodificación del Código, es la utilización de las categorías delitos y cuasidelitos, por la de responsabilidad civil. 
artículo 1382 se refiere al "fait" (hecho), que la doctrina ha interpretado como actuación dolosa, mientras que el artículo siguiente menciona a la négligence o la imprudence, desde donde puede deducirse que la primera norma se refiere a los delitos y la segunda a los cuasidelitos, sin existir en la disposición una vinculación explícita. Es por ello que los autores piensan que la faute vino a constituir un genus que comprendía tanto las figuras dolosas, como culposas y que, además, para referirse a esta última, los redactores utilizaron las expresiones imprudence o négligence ${ }^{54}$.

Desde este punto de vista, es posible afirmar que los codificadores franceses no fueron completamente fieles a Domat, contrariamente a lo que sostienen Mazeaud y Tunc, puesto que Domat utilizó la expresión faute para referirse a la culpa estricta, debido a que entendía que los delitos se encontraban fuera del campo de la responsabilidad por daños. De este modo, la faute no equivalía para este autor, en caso alguno a la culpabilidad ${ }^{55}$.

En consecuencia, cuando Domat establece la regla general de responsabilidad fundada en la culpa, lo hace considerándola culpa estricta y no el dolo ${ }^{56}$. Así, Domat señala: “Toutes les pertes \& tous les dommages qui peuvent arriver par le fait de quelque persone, soit imprudence, légereté, ignorance de ce qu'on doit sçavoir, ou otres fautes semblables, si légeres qu'elles puissent être, doivent être réparées par celui dont l'imprudence ou autre faute y a donné lieu. Car c'eft un tort qu'il fait, quand même il n'auroit pase u intention de nuire" 57 .

Con todo, puede ser ensayada una segunda explicación, desde nuestra perspectiva más correcta. Domat empleó la faute para referirse a la negligencia o la imprudencia, en definitiva, a la culpa estricta. Dicha equivalencia responde a las ideas filosófico-religiosas de este autor. Ahora bien, desde esta nueva perspectiva, puede concluirse que los redactores del Código quisieron separarse de la óptica domatiana, por cuanto, a diferencia de la tesis tradicional, consideramos que es posible sostener que la faute no fue empleada con un sentido genérico, comprensiva tanto del dolo, como de la culpa estricta. Por el contrario, dicha expresión fue utilizada por los redactores en su sentido ordinario, al haber incorporado los delitos civiles, fundados en el dolo, al terreno civil, siguiendo a Pothier. Así, es notorio que la faute solo es mencionada en el artículo 1382, a propósito de las actuaciones consideradas dolosas. Precisamente, en su sentido ordinario, faute o falta implica una conducta intencional. En cambio, el artículo 1383 simplemente se refiere a la imprudencia y la negligencia y en los restantes articulados no vuelve a emplearse la expresión faute.

\footnotetext{
54 De este modo, la doctrina distingue entre faute intentionnelle y faute no intentionnelle. Sobre el punto, por todos, Planiol y Ripert (1952) p. 642 y más modernamente, Thiry (2005) pp. 75-79.

55 Ya en el Traite des Loix, cap. VIII, III Domat diferenció entre las consecuencias penales de un ilícito, destinada a corregir a los culpables y la reparación de los perjuicios. La distinción entre las tres fuentes, es decir, el ilícito penal, los daños causados sin convención y los perjuicios derivados de una convención entre las partes, se encuentran en Domat (1776) P. I, L. II, tít. VIII: "On peut distinguer trois sortes de fautes dont il peut arriver quelque domage. Celle qui vont à un crime ou à un delit: celles des personnes qui manquent aux engagements dês conventions, comme un vendeur qui ne delivré pás la chose vendue, un locataire qui ne fait pás la réparations dont il est tenu: \& celle qui n'ont point de rapport aux conventions, \& qui ne vont pas à un crime ni à un délit; comme si par légéreté on jette quelque chose par une senêtre qui gâte un habit: si des animaux mal gardés sont quelque domage..."

56 Véase, en este sentido, Tale (1997) p. 1 y Tale (2003) p. 129.

57 Domat (1776) P. I, L. II, tít. VIII, sec. IV, I.
} 
Una posible objeción a la proposición de este trabajo, se encuentra nuevamente en la tesis tradicional. Entre los autores franceses hay unanimidad en el sentido que Domat exigió una faute en todos los supuestos. Como dice Viney, en el espíritu de Domat la faute no constituye solo la condición de responsabilidad, sino también su medida ${ }^{58}$. Sin embargo, hay autores que estiman que en algunos casos - precisamente, las que se corresponden con las de quasi ex delicto- Domat habría admitido un grado de responsabilidad estricta, al punto que la misma Viney señala que el jurista francés parece ser el primero que avanza sobre la noción de riesgo creado, quien sigue en este punto a Husson ${ }^{59}$.

A nuestro juicio, estos puntos de vista no pueden asumirse tratándose de los cuasidelitos romanos de acuerdo con el tratamiento de Domat, pues él mismo advierte que la aplicación de las disposiciones anteriores supone la existencia de descuido (mégarde) y sin que concurra la intención de dañar, en cuyo caso, debe aplicarse la sanción penal, sin perjuicio de las consecuencias civiles. Es cierto que no utiliza la expresión faute, pero sí hay una clara indicación a la culpa. Según el autor: "Tous les articles précédens séntendent de ce qui a été jetté ou répandu par mégarde \& sans aucun dessein. Que sill y a du dessein, l'injure, le délit ou crime será reprimé par de plus greives peines, felon la qualité du fait \& les circonstances"60.

Por último, las normas que finalmente recoge la codificación desechan varias de las reglas sustentadas por Domat. Si continuamos con el análisis de la obra de Domat, podemos apreciar que antes de enunciar su regla general, fundada en la culpa, Domat trata muchos supuestos específicos recogidos de acciones romanas ${ }^{61}$. El Code, aun cuando utiliza la expresión y a diferencia de proyectos anteriores, no incorporó ninguno en su regulación y de hecho, del proyecto se eliminó precisamente cualquier tratamiento casuístico.

\footnotetext{
58 Véase, en este sentido y por todos Viney y Jourdain (1998) p. 14.

59 Viney y Jourdain (1998), p. 14. Sobre esta opinión, véase Husson (1947) pp. 165 y ss. En el mismo sentido, Tale (1997) p. 2 y Tale (2003) pp. 130-131. Como señala Gordley (1994) pp. 459-479; 483-505, esta misma ambigüedad habría sido trasportada al Code, que presenta casos en los que no se exigiría culpa. Incluso, tales vacilaciones se extenderían a todos quienes intervinieron en el proceso codificador. De un lado, Bertrand de Greuille sostiene que la responsabilidad de los maestros y empleadores estaba fundada en un factor objetivo; de otro Tarrible y Treilhard, parecerían fundar la responsabilidad exclusivamente en la culpa. Por el contrario, tales ambigüedades no se encuentran en los primeros comentadores del Code, que afirmaron la exigencia de la culpa en todos los casos.

60 Domat (1776) P. I, L. II, t. VIII, sec. I, VIII.

61 Así, Domat utiliza continuamente las expresiones imprudence o négligence, reconducibles al concepto general de la faute. Los números II-X se preocupan de detallar el principio general consagrado en el numeral I de la sección IV. Veamos algunos ejemplos. En el número III, Domat se refiere a los daños causados de manera imprevista a un inocente. Dichos perjuicios no pueden imputarse a nadie, desde que no existe falta, pero si junto con las demás circunstancias puede apreciarse imprudencia, el autor de esta, pese a no ser la única causa del perjuicio, debe resarcirlo. En el número IV, Domat se refiere a los daños causados por obras: En efecto, en dicho numeral Domat señala: "Ceux qui sont quelques ouvrages o quelques travaux, d'ou il peut suivre quelque dommage à d'autres personnes, en seront tenus, sills n’ont usé des précautions nécessaires pour le prévenir”. Por último, en el número V se refiere a la impericia. Una vez más, se trata de la generalización de los casos del Digesto en los que se deciden cuestiones relativas conductas dañosas cometidas con impericia, en D. 9, 2, 7, 8 y D. 9, 2, 27, 33. Según Domat: "Il faut mettre au nombre des dommages causés par de fautes, ceux qui arrivent par l'ignorance des choses que l'on doit f̧̧avoir”. Véase Domat (1776) P. I, L. II, t. VIII, sec. IV, III, IV y V.
} 


\section{CONCLUSIONES}

El presente trabajo nos sugiere las siguientes conclusiones:

a) La codificación se presenta como una obra compleja y simbiótica, que admite desde luego varias lecturas, pero debe reconocerse en dicho cuerpo normativo las inspiraciones, a menudo contradictorias, entre un Estado que quiere gobernar, a través de la ley, las corrientes autoritarias que devienen, por tanto, del Estado nacional y los afanes liberales propios del humanismo y del iusnaturalismo racionalista.

b) No puede ponerse en duda que el Code y, en particular, la responsabilidad civil, es de clara inspiración iusnaturalista racionalista. De hecho, la cláusula general de responsabilidad es obra de esta corriente filosófica, cuyo punto de partida es, como es sabido Grocio, pero que, en su contenido, es decir, en las nociones de acto, culpa, iniuria, causalidad y daño, bebieron de las fuentes romanas, especialmente de la lex Aquilia.

c) Tampoco se puede desconocer que la confección de sus normas, algunas fueron inspiradas en la sistematización de Domat. El método de este autor importó una sistematización, generalización y racionalización de las reglas romanas (casuísticas), pero separándose de la secularidad que implicaba una fe completa en la razón, como postulaba el iusnaturalismo racionalista.

d) No obstante, desde ahí no puede asumirse que las disposiciones del Code siguieran la perspectiva filosófica, moral y antropológica de Domat en materia de responsabilidad civil y, particularmente, a propósito de la faute.

e) En este trabajo se han dado tres órdenes de razones: en primer lugar, un grupo de argumentos de índole metodológicos, por cuanto en Domat no puede considerarse un iusnaturalista racionalista. El principal rasgo de la corriente está ausente en Domat, pues el autor ensaya una fundamentación trascendente para el Derecho y su dialéctica es jansenista (la razón corrompida del hombre), que le lleva a la adopción de los primeros principios por intuición. Si existe esta gran diferencia de método, uno debería esperar que la inspiración moral de las normas del Code sea distinta.

f) Un segundo grupo de argumentos guarda relación con la perspectiva pesimista de la naturaleza humana. Cierto es que el Code puede compartir con la obra de Domat esta perspectiva, especialmente en la lectura jansenista, pero sus fuentes son diferentes: ni el Code se inspira antropológicamente en el jansenismo, ni Domat lo abrazó completamente.

g) Y finalmente, un tercer orden de argumentación guarda relación con la comparación entre la obra de Domat y el Code. Como efectivamente ha intentado demostrarse en este artículo, el empleo de la expresión faute en Domat (asimilándola al negligencia o imprudencia), es muy distinto al empleo que el Code le da en sus normas (limitándola, a nuestro juicio, a las conductas dolosas).

h) Juzgamos que nuestro enfoque es original, en el sentido de que se ha hecho un esfuerzo sistematizador que permite abonar argumentos en favor de la unidad conceptual histórica de la culpa, poniendo en cuestión la tesis tradicional, mayoritariamente sostenida tanto para el sistema codificado francés, como para el chileno, en términos que la culpa y su consagración codificada obedeció a razones exclusivamente morales derivadas de las influencias canónicas o bien que esta representaba un reproche exclusivamente moral. Por la 
misma razón, como se ha concluido antes, se ha rechazado el criterio con arreglo al cual, el Code y, como consecuencia, todo el proceso codificador hizo suyo el enfoque ético religioso de Domat, lo que a nuestro juicio carece de base suficiente.

\section{BIBLIOGRAFÍA CITADA}

Albanese, Bernardo (1992): "Recensioni critiche a Valditara. Superamento dell'aestimatio rei nella valutazione del danno aquiliano ed estensione della tutela ai non domini", IURA, N43: pp. 244-248.

Aedo Barrena, Cristián (2009): "Los requisitos de la Lex Aquilia, con especial referencia al daño. Lecturas desde la distintas teorías sobre el Capítulo Tercero", Ius et Praxis, Año 15, $\mathrm{N}^{\circ} 1$ : pp. 311-337.

Aedo Barrena, Cristián (2011): "La ampliación de la legitimación activa en la lex Aquilia, a través de las acciones in factum y útiles", Revista General de Derecho Romano, N ${ }^{\circ} 17$ : pp. 1-19.

Aedo Barrena, Cristián (2012): "La función de la culpa en el sistema de responsabilidad civil: una lectura desde el Derecho romano es posible", en Elorriaga DE Bonis, Fabián (coordinador), Estudios de Derecho Civil VII, Jornadas Nacionales de Derecho Civil IX (Santiago, LegalPublishing).

Aedo Barrena, Cristián (2014): "El concepto de culpa aquiliana y su evolución en las últimas décadas. Distintas teorías", Revista de Derecho de la Universidad Católica del Norte, vol. 21, No 2: pp. 21-59.

ARNAUD, André-Jean (1969): Les origins doctrinales du Code civil français (Paris, LGDJ).

Auzhary-Schmaltz, Bernadette (1999): "La responsabilité délictuelle dans l'ancien droit français. Les origines des articles 1382 et suivants du Code Civil”, Revue historique de droit français et étranger, vol.77, No 2: pp. 163-190.

Bascuñán Rodríguez, Antonio (2013): "El mito de Domat", en Atria Lemaitre, Fernando, Correa González, Rodrigo, López Masle, Julián y Sierra Iribarren, Lucas (Comité editorial), Una vida en la Universidad de Chile. Celebrando al profesor Antonio Bascuñán Valdés (Santiago, Thomson Reuters) pp. 263-349.

Biond, Biondo (1954): Il diritto romano cristiano III: La famiglia. Rapporti patrimoniali. Diritto pubblico (Milano, Giuffrè).

Bussi, Emilio (1937): La formazione dei dogmi di Diritto privato nel diritto comune, vol. I: Diritto reali e diritti di obbligazione (Padova, Cedam).

Carbonier, Jean (2004): "Le Code civil", en AA.VV. Le Code Civil. 1804-2004. Livre du Bicentenaire, Dalloz (Paris, LexisNexis-Litec).

CARONI, Pio (1996): Lecciones catalanas sobre historia de la codificación (trad. por Aquilino Iglesia Ferreirós, Madrid, Marcial Pons).

Carpintero Benítez, Francisco (2000): Historia breve del Derecho Natural (Madrid, Colex).

Cornu, Gérard (2005): Vocabulaire juridique (Paris, PUF, séptima edición).

Corradini, Domenico (1971): Garantismo e Statualismo (Milano, Giuffrè).

Cousin, Víctor (1845): Documents inédits sur Domat, Tomo IV: Premiere partie (Bruxelles). 
Descamps, Olivier (2008): "Le destin de l'article 1382 ou: de la Fable du chêne et du roseau en materie de responsabilité civile", Droits: Revue Francaise de theorie juridique, de philosophie et de culture juridiques, No 47: pp. 23-44.

Domat, Jean (1766): Les loix civiles dans leur ordre naturel; Le Droit Public et Legum Delectus, (Paris, A. Paris, cez la Veue Cavalier).

Duguit, León (1920): Las transformaciones generales del Derecho privado desde el Código de Napoleón (trad. de Carlos Posada, Francisco Beltrán (Edit.), Madrid, segunda edición).

Fenet (1856): Recueil complet des travaux préparatoires du Code Civil (París, Videcoq Libraire).

Filomusi Guelfi, Francesco (1949): "La codifizione civile e le idee moderne che ad essa si riferiscono”, en DEL VeCCHIO, Giorgo (a cura di), Lezioni e saggi di Filosofía del diritto (Milano, Giuffrè).

Furet, François y Ozouf, Mona (1989): Diccionario de la Revolución Francesa (trad. de Jesús Bravo, Néstor Míguez, Mauro Armiño, Daniel de la Iglesia y Ricardo Artola, Madrid, Alianza Editorial).

Gilles, David (2009): "Les lois civiles de Jean Domat, prémices à la Codification. Du Code Napoléon au Code civil du Bas Canada", Revue Juridique Thémis, No 43: pp. $1-49$.

Gómez Arboleya, Enrique (1951): "El racionalismo jurídico y los Códigos europeos. Segunda parte", Revista de Estudios Políticos, No 60: pp. 33-66.

Gordley, James (1994): "Myths of the French Civil Code", The American Journal of Comparative Law, XLII: pp. 459-505.

GuZmán Brito, Alejandro (2004): "La doctrina de Jean Domat sobre la interpretación de las leyes", Revista Chilena de Derecho, vol. 31, No 1: pp. 39-68.

Halpérin, Jean Louis (1992): L'impossible Code Civil (Paris, PUF).

Halpérin, Jean Louis (1996): Le Code Civil (Paris, Dalloz).

Halpérin, Jean Louis (2004): "Le regard de l'Historien”, en AA.VV. Le Code Civil. Livre du Bicentenaire (Paris, Dalloz) pp. 43-58.

Hazard, Paul (1963): La pensé européenne au XVIII siécle: de Montesquieu a Lessing (Paris, Fayard).

Hesphana, António Manuel (2002): Cultura jurídica europea. Sintesis de un Milenio, (trad. Isabel Soler y Concepción Valera, Madrid, Tecnos).

Husson, León (1947): Les transformations de la responsabilité. Étude sur la pensé juridique (Paris, Lettres).

JaCQUEMET, G. (dirigée par) (1952): Catholicisme. Encyclopédie en sept volumes, Confréries de Charité-Éléphantine, Tomo 13 (Paris, Letounez et Ané).

LotTin, Odon (1954): Morale fondamentale (Lovaina, Desclée \& Cie).

Matteucci, Nicola (1959): Jean Domat un magistrato giansenista (Bolonia, Il Mulino).

Martin, Xavier (1982): "L'insensibilité des rédacteurs du Code civil à l'altruisme", RHD, N60: pp. 589-618.

Martínez, Betty (2008): "La faute y la culpa", en Mantilla Espinosa, Fabricio y Pizarro Wilson, Carlos (coordinadores), Estudios de Derecho Privado en homenaje a Christian Larroumet (Santiago, Fundación Fernando Fueyo Laneri) pp. 275-298. 
Martínez Serra, Vicente (2000): "El socialismo ético personalista de Emmanuel Mounier y Jean Lacroix”, Cuadernos de Trabajo Social, N 13: pp. 91-108.

Mazeaud, Henri, Mazeaud, Leon y Mazeaud, Jean (1978): Lecciones de Derecho Civil Part. II, vol. II: La responsabilidad civil. Los cuasicontratos (trad. por Luis Alcalá Zamora y Castillo, Buenos Aires, Montchrestein).

Mazeaud, Henri, Mazeaud, Léon, Tunc, André (1977): Tratado teórico y práctico de la responsabilidad civil delictual y contractual, Tomo I, Volumen I (trad. de la $5^{\text {a }}$ edición francesa por Santiago Sentis Melendo, Buenos Aires, Ediciones Jurídicas Europa-América).

Passerin d'Entrevés, Alessandro (1965): Natural law. An historical survey (New York, Harper Torchbooks).

Planiol, Marcel y Ripert, Georges (1952): Traité pratique de Droit Civil Français, Tomo XVI: Obligations, Prémiere Partie (Paris, LGDJ).

PORTALIS, Jean Etienne Marie (1997): Discurso preliminar al Código civil francés (trad. por I. Cremades y L. Gutiérrez Masson, Madrid, Civitas).

Poughon, Jean Michel (1992): Le Code Civil (Paris, PUF, décima edición).

Renoux-Zagmé, Marie-France (1993): "Domat: du jugement de Dieu à l'esprit des lois", Le Débat, No 74: pp. 54-68.

Renoux-Zagmé, Marie-France (2004): "La figure du judge chez Domat", Droits: Revue Francaise de theorie juridique, de philosophie et de culture juridiques, No 39, vol. 1: pp. 35-52.

Ripert, Georges y Boulanger, Jean (1965): Tratado de Derecho Civil, según el Tratado de Planiol, Tomo V: Obligaciones (trad. de Delia García Daireaux, Buenos Aires, La Ley).

Ricoeur, Paul (2005): "La lutte pour la reconnaissance et l'economie du don", en Agís Villaverde, Marcetili, et al. (coords.), Hermenéutica y responsabilidad. Homenaje a Paul Ricoeur (Santiago de Compostela, Universidad de Santiago de Compostela) pp. 29-40.

Rogel Vide, Carlos (2010): Derecho Civil -método y concepto- (Bogotá, Mexico, Madrid, Buenos Aires: Temis-Ubijus-Zavalia).

Sarzotti, Claudio (1995): Jean Domat. Fondamento e método della scienza giuridica (Torino, Giappichelli).

Savatier, R. (1927): L'art de faire les Lois. Bonaparte et le Code Civil (Paris, Librairie Dalloz).

SAVATIER, René (1959): Les metamorphoses économiques et sociales du droit privé d'aujourd'hui (Paris, Dalloz).

Tale, Camilo (1997): "El conocimiento de la ley natural y la obligatoriedad de la ley positiva en Jean Domat", Sapientia, vol. LII, N 202: pp. 289-306.

Tale, Camilo (2003): "El Derecho de daños en Jean Domat”, en VV.AA. La codificación: raices y prospectivas (Buenos Aires, EDUCA) pp. 127-145.

TARELlo, Giovanni (1976): Storia della cultura giuridica moderna, Tomo I: Assolutismo e codificazione del diritto (Bologna, Il Mulino).

THIRY, Bernard (2005): Diccionario jurídico: terminología de la responsabilidad civil (español-francés; francés-español) (Granada, Publicaciones Universidad de Granada).

Todescan, Franco (2014): Le radici teologiche del giusnaturalismo laico. Il problema della secolarizzazione nel pensiero giurico del sec. XVII (Padova, Cedam). 
Urbano Salerno, Marcelo (1996): "Culpa y sanción”, en Kemelmajer de Carlucci, Aída (Dir.) y Parellada, Carlos (coordinador), Derecho de Daños, Segunda parte (Buenos Aires, La Rocca) pp. 279-285.

Viney, Geneviève y Jourdain, Patrice (1998): Traité de Droit Civil. Les conditions de la responsabilité (Paris, LGDJ, segunda edición).

VINEY, Geneviève (2004): "Les difficultés de la recodification du droit de la responsabilité civile", en A.A.V.V. Le Code Civil. 1804-2004. Livre du Bicentenaire (Paris, Dalloz, LexisNexis-Litec) pp. 255-281.

Welzel, Hans (1977): Introducción a la flosofía del derecho: derecho natural y justicia material (trad. de Felipe González Vicén, Madrid, Biblioteca Jurídica Aguilar, 2a reimpresión de la segunda edición).

WIEACKer, Franz (1995): A History of Private law in Europe. With particular reference to Germany (trad. de la edición alemana de 1908 por Tony Weir, Oxford, Clarendon Press). 
